\title{
Supporting Climate-Resilient Planning at National and District Levels: A Pathway to Multi-stakeholder Decision-Making in Uganda
}

\author{
Rosalind J. Cornforth, Celia Petty, and Grady Walker
}

\begin{abstract}
If rural adaptation is to be effective, then it cannot take the form of prescriptive actions determined by outsiders and subsequently imposed upon rural communities. Our focus in this chapter is to reflect on the effectiveness of rural adaptation in the context of food security and agriculture in Uganda and provide insight into a way forward using learning from the HyCRISTAL project rural pilot. We critically explore the boundaries of 'adaptation' and 'resilience' as policy responses to climate change in poor rural communities through the interdisciplinary use of quantitative and qualitative methodologies, including innovative visual methods and action research. We identify some of the limits to building adaptive communities and explore potential solutions for enabling informed decision-making for rural adaptation that are linked to investment in
\end{abstract}

\footnotetext{
R. J. Cornforth $(\bowtie) \bullet$ C. Petty $\bullet$ G. Walker

Walker Institute, University of Reading, Reading, UK e-mail: r.j.cornforth@reading.ac.uk

(C) The Author(s) 2021

D. Conway, K. Vincent (eds.), Climate Risk in Africa, https://doi.org/10.1007/978-3-030-61160-6_8
} 
sustainable development. We highlight the importance of multi-stakeholder approaches and the generation of a 'knowledge ecosystem' that combines physical and social science methods and data to generate context-specific information to inform decision-making.

Keywords Climate resilience $\bullet$ Livelihoods $\bullet$ Africa $\bullet$ Climate information • Rural adaptation $\bullet$ Decision-making • Uganda

\section{INTRODUCTION}

Effective rural adaptation to climate change and variability depends on a multi-stakeholder approach to climate-informed decision-making, contextualised by local circumstances, and supported by new approaches to the generation and synthesis of interdisciplinary knowledge from across the physical and social sciences. Getting the different sectors working together is, however, difficult. As Boyd and Cornforth (2013) observe, 'Climate research is often communicated at global or regional levels, whilst lessons from livelihood projects are often relevant at the national context only' (p. 201). However, such barriers may be overcome when a wide variety of actors, including physical scientists, social scientists and in-country decision-makers-from ministers to smallholder farmers-commit to work together and share their knowledge and experience (e.g. Mitchell and Maxwell 2010; Jarvis et al. 2011).

Climate change issues threaten ongoing development efforts in Uganda, which is already experiencing the negative impacts of climate variability (Markandya et al. 2015). Droughts in 2008, 2010 and 2016-17 caused significant losses. In 2010, the economic losses were approximately US $\$ 470$ million, equivalent to $16 \%$ of the total annual value of crops and livestock. In 2019, significant losses occurred in certain districts due to a combination of floods, landslides, crop pests and diseases and hailstorms (UNOCHA 2019).

Recognising the threat of climate change, the government of Uganda has made commitments to reduce climate risk. The National Vision 2040 and National Development Plan (NDPII) both make provisions for mitigation and adaptation (Uganda Government 2015a). Although there is a climate change policy in place (Uganda Government 2015b), the National Climate Change Bill has not yet been finalised, and pressures on financial resources impede effective implementation and monitoring of activities. Early discussions with the National Early Warning Co-ordination Centre, 
the Uganda National Meteorological Agency (UNMA) and other stakeholders from national to village level highlighted a knowledge gap in terms of realistic scenarios of the potential impacts of climate change, among other things.

To address this gap, the Integrating Hydro-Climate Science into Policy Decisions for Climate-Resilient Infrastructure and Livelihoods in East Africa (HyCRISTAL) rural pilot described in this chapter maps out a practical pathway to multi-stakeholder decision-making, drawing together knowledge and insight from both the social and physical sciences, to develop realistic scenarios of potential climate change impacts on defined populations and guide policy decisions. The research took place in Mukono District, east of Kampala, Uganda's capital and largest city, bordering the shores of Lake Victoria. We present the structure and form of the pathway to multi-stakeholder decision-making, then outline how this pathway was applied in Mukono, and the outcomes, and, finally, reflect on the utility of this approach in enabling effective adaptation and resilience.

\section{A Pathway to Multi-stakeholder Decision-Making}

Developing realistic scenarios required the integration of long-term hydro-climate projections with local context-specific information. We adopted an integrated approach with four key elements, depicted in the outer circle of Fig. 8.1: Research; Technology and Data; Capacity Building; and Governance. Each element then played a contributing part in developing an understanding of context and communication pathways to inform improved decision-making for climate resilience at the national and local levels (Fig. 8.1). The engagement was facilitated by Climate Action Network-Uganda (CAN-U), a locally based climate action advocacy organisation, which established a network of farmer (and fisher) champions to represent local perspectives and subjectivities concerning adaptation strategies.

Interdisciplinary Research involved rural livelihoods modelling-to develop plausible scenarios of the potential impact of climate change on the defined populations, combined with an understanding of the historical drivers of change in the land, natural resources and population dynamics in the Lake Victoria Basin.

Rural livelihoods modelling was informed by the Sustainable Livelihoods Framework and Household Economy Approach (HEA). The idea of sustainable livelihoods recognises that people's livelihoods result from the different types of livelihood assets or 'capitals' (physical, social, financial, 


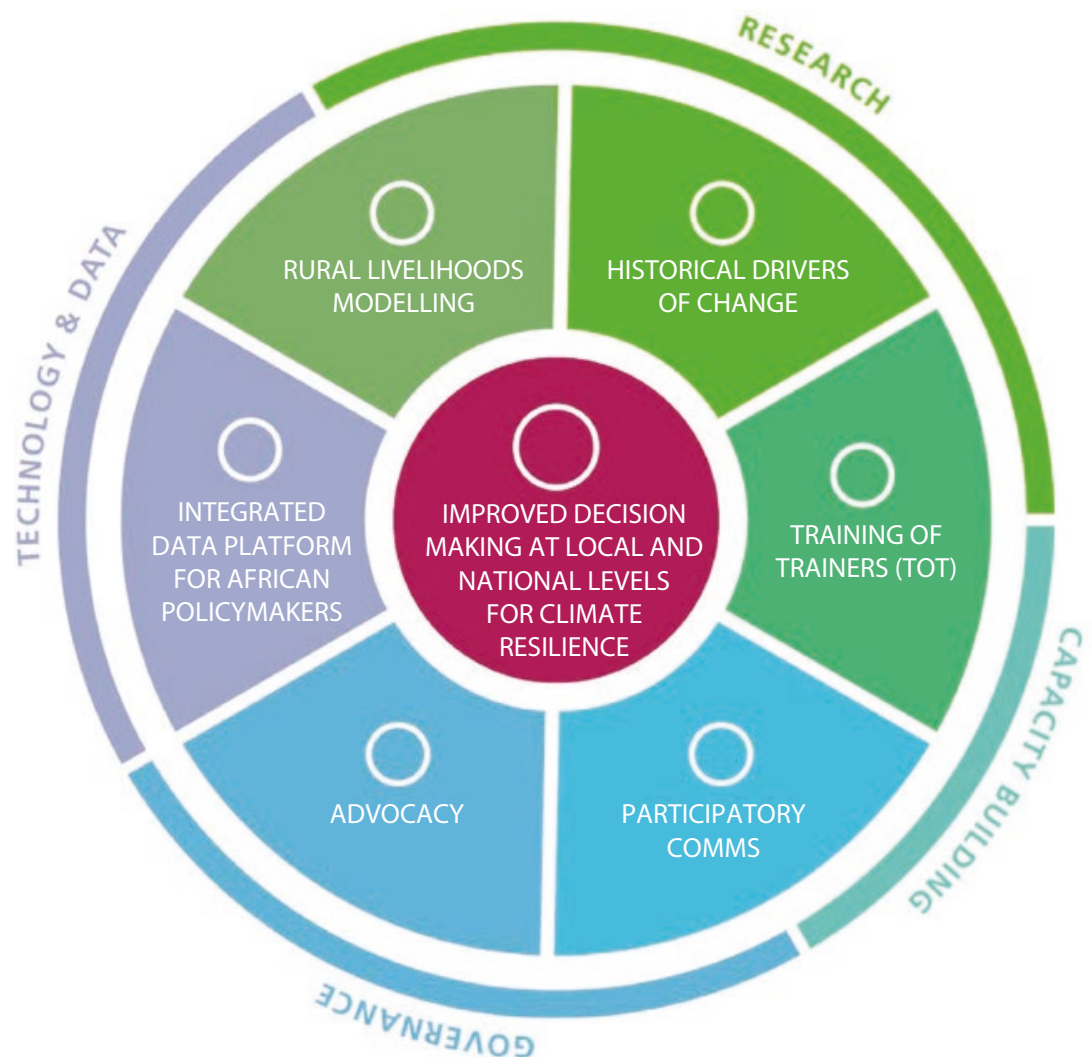

Fig. 8.1 Multi-stakeholder engagement approach and mixed-method research design

natural and human) on which they are able to draw, and that institutions mediate the capacity to convert those capitals into livelihood outcomes (Chambers and Conway 1992; Scoones 1998; Ellis 2000). It thus draws on Sen's Entitlement Theory (Sen 1981). The HEA complements sustainable livelihoods by providing a practical, field-based methodology to quantify income generated by households in 'livelihood zones' based on the assets and opportunities available to them and the ways in which they are used to generate food, food stocks and income (Seaman et al. 2014). The HEA is designed to allow short run predictions of the impact of production, price, and other year-to-year changes in the income and welfare 
of rural households. A modified version that is based on the same conceptual framework-the Individual Household Method (IHM)-is applied at a finer spatial resolution, namely single study villages rather than livelihood zones, and allows for more detailed analysis of differences within and between households across the wealth distribution.

The Technology and Data component involved integration of the different physical and social science data streams (climate, hydrology, agriculture and livelihoods) in HyCRISTAL through the Integrated Database for African Policymakers (IDAPS) platform. Analysis and sharing of local contextualised knowledge on IDAPS enabled decision-makers at the National Planning Authority (NPA) to explore realistic 'what if' scenarios.

Building Capacity occurred through 'Training of Trainers' conducted in partnership with local institutions and partner universities in HEA data collection and IDAPS analysis. This helped to accelerate, grow and sustain IDAPS adoption and ensure local institutions can continue to deliver both HEA and IDAPS training, with a view to post-project sustainability.

Governance involved the use of targeted advocacy and innovative participatory media communications and visual methods and action research approaches to influence relevant national and local decision-making processes. At the national level, processes that were informed include the National Development Plan, the National Environment Management Bill and the Koronivia Joint Work on Agriculture (a process taking place under the United Nations Framework Convention on Climate Change [UNFCCC] to address climate and agriculture issues). At local level, the target audience was district budgetary allocation committees supporting adaptation planning within the communities.

\section{Applying the Pathway to Multi-stakeholder Decision-Making in Mukono: Process and Outcomes}

\section{Interdisciplinary Research: Developing Plausible Scenarios of the Potential Impact of Climate Change on Defined Populations}

Data for rural livelihoods assessment and climate impact modelling were collected using the HEA. Workshops held in Mukono were used to identify livelihood zones. Livelihood zone data were then collected through interviews conducted in groups at the community level for a defined 'reference year' (in this case May 2015-June 2016). This was the most recent year that community members identified as being neither particularly bad 
nor particularly good for production. Wealth group interviews yielded data for a household 'typical' of the wealth group and included household asset holdings, a household budget including all sources of income and necessary supporting data such as household membership, market prices, information on additional sources of income that households might exploit under conditions of economic stress, seasonality and the price of food and non-food goods. This dataset could then be used to explore the expected impact of changed hydro-climate conditions on 'typical' household income (Seaman et al. 2014) using the IDAPS platform.

Additional detailed household economy information was collected using the IHM. In addition to the IHM interviews, focus group interviews covering adaptation and historical livelihood change were conducted, disaggregated by age and gender, which provided additional insight into 'adaptive' livelihood responses to climate and non-climate related events (e.g. the collapse in global coffee prices in the late 1990s, coffee wilt disease, banana mosaic disease and reduced maize yields due to changes in seasonal rainfall), and the social and cultural, as well as financial considerations that played a part in shaping these changes. This information provides insights into the extent to which future hydro-climate conditions are likely to be tolerated within existing adaptive capacity, and where further adaptive capacity might need to be strengthened.

Collecting data on household resilience and vulnerability is essential to contextualise modelling data and generate locally appropriate scenarios. In this case, findings of the HEA and IHM analysis on the contribution of specific crops and fishing to household food security across the income distribution provided a quantitative indication of household sensitivity to different climate risk scenarios. This identified that wrong assumptions had been made at the project's design phase (which included local climate scientists and fisheries experts, as well as physical scientists based in the UK) regarding the balance between fishing and agriculture in the rural economy of households living in lakeshore communities and the immediate hinterland which, if they had been used in a single disciplinary manner, could have been misleading.

Feedback sessions and dialogue with local farmers identified potential growth areas for smallholder incomes and barriers, together with possible solutions, to reduce climate risk. Examples included improving market access through investment in rural infrastructure or upgrading rural extension services and improving pest control. 
The more detailed IHM studies generated financial analysis of the costs and affordability of various adaptation options available locally, showing that over $50 \%$ of the study population had disposable incomes that were well below the level needed to invest in activities that yielded even modest returns. For the poorest $25 \%$ of households, 'negative coping' often involving illegal or semi-legal activities, with unavoidable risks to both individuals and the environment, was the only available response to income shocks. Again, a single disciplinary approach would have missed this reality and may have resulted in recommendations for adaptations that would not have been affordable to the majority of the population.

As well as affordability, the qualitative data generated through focus groups highlighted how socially constructed gender roles and responsibilities may also lead to differential access to proposed adaptation strategies by women and men. With the collapse of income sources traditionally managed by men (e.g. coffee, bananas, fish), the lives of a generation of women now in middle age have been profoundly changed. Social conventions that had limited their work to the domestic sphere were dropped as they took up petty trade and small-scale enterprise in order to put food on the table. A short ethnographic study to engage with different people's present-day, lived experiences of these realities enabled understanding of the opportunities and constraints they place on their adaptive practices. This is essential to avoid recommending adaptation strategies that are either not accessible to all, or would act to reinforce existing gender inequalities.

\section{Technology and Data: Preparation for Uncertainty Through Realistic 'What If' Scenarios Using IDAPS}

Working with the National Emergency Coordination and Operations Centre (of the Department of Disaster Preparedness and Management) and stakeholders from national to village level, the IDAPS multi-sector data platform was developed (Cornforth et al. 2020). The platform is open data and cloud-based and is intended to be freely accessible to stakeholders at every level. The purpose of the platform is to democratise access to information and allow local decision-makers to create and explore their own scenarios for planning and climate-impact preparedness and adaptation. 


\section{Box 8.1 Stepwise Development of IDAPS}

The first IDAPS user forum was hosted in 2017 by the Uganda National Council for Science and Technology (UNCST). Key attendees included four Members of Parliament, including Honourable Cecilia Atim Ogwal (Deputy Speaker) and the leader of the Parliamentary Forum on Climate Change; the Assistant Commissioner, Ugandan Ministry for Water and Environment (MWE); Deputy Executive Secretary of UNCST; a senior representative from Uganda's National Emergency Coordination and Operations Centre; representatives of civil society climate change advocacy groups; and senior district level technical officers.

This wide-reaching stakeholder engagement was the first step towards ensuring that the IDAPS platform is accessible and applicable to a diverse group of users, a necessary condition for successful and well-informed decision-making. Subsequent steps have focused collective efforts on co-developing, refining and prioritising Use Cases to include on IDAPS. Here, a Use Case, at the highest level, has the simple formula:

$$
\text { As a } \mathrm{X} \text { (a role), I need Y (a feature), to do Z (a benefit) }
$$

IDAPS then brings together the most relevant data sets from across different disciplines to satisfy a prioritised Use Case (for a role). These data are then presented in a way (the feature) that is meaningful to the non-specialists enabling them, for the first time, to interact with the data and develop scenarios based on their own perceptions of plausible futures (the benefit).

IDAPS brings together data from climate modelling, agronomy and hydrology to model the impact of climate scenarios on people's livelihoods and their ability to access their basic food and non-food needs. The HEA and IHM outlined earlier were used to model the impact of climate and other shocks on rural livelihoods in order to understand who would be affected, and in what ways, by a defined change scenario in a specific livelihood zone. At a national level, by contributing to a deeper understanding of the likely impact of climatic change on people's livelihoods in 
particular districts throughout Uganda, the possibility of delivering timely national responses (Cornforth et al. 2020) that are tailored for appropriate mitigation and adaptation strategies should be greatly enhanced.

IDAPS visualisations and decision Use Cases have been meaningfully co-produced with government and civil society stakeholders at the national, district and sub-district levels to develop a set of Stakeholder Value Narratives (Fig. 8.2). The first IDAPS module (the HEA) has been successfully used in a pilot project. The second module (IHM) has also been completed, and allows for more detailed analysis, monitoring and evaluations at an individual household level. New modules of IDAPS are in development for use in climate change scenario impact modelling, which integrate hydrological and meteorological data to support policy decisions for the sweet potato market (Young et al. 2020). The first of these has been used to examine the government interventions that might be needed in the context of a wetter and warmer climate, that is to say, 'Future 1' in the HyCRISTAL Climate Narratives (see Burgin et al. 2019).

\section{Capacity Building}

For a decision-making tool such as IDAPS to be effective, and for additional modules to be developed for use in other districts, it is necessary to provide training in HEA data collection and IDAPS analysis. Currently, engagement with policymakers and administrator stakeholders in Uganda is deepening with 'Training of Trainers' capacity building work ongoing. The interview frameworks and data analysis methods used in HEA and IHM studies have been designed to be easily taught, and training curricula have been developed with local universities.

\section{Governance and Advocacy: Scaling Up Co-management and Social Learning Through Participatory Communications (Visual Methods Research)}

Advocacy and awareness raising activities are proceeding in concert with capacity building. The facilitator of the process, CAN-U, has strong government links and advocacy experience. A high-impact advocacy plan was co-developed, aimed at communicating and influencing decision-making on rural adaptation at the sub-national and national levels in Uganda, guided by the findings from the rural pilot research. Working together with CAN-U, direct proposals were made to the Climate Change Working 
Group during the consultative process for the Ugandan National Environment Bill. In making suggested revisions and additions to relevant clauses in the bill, the team were able to signal the need for comprehensive livelihoods zoning and the prerequisite of having a deep, balanced and uniform baseline understanding of livelihoods before any of the impacts of climate change on society and the economy might be fully understood. ${ }^{1}$

Together with CAN-U, a network was also developed of farmer (and fisher) champions who were in a position to represent local perspectives and subjectivities concerning adaptation strategies. Eight community farmer champions based in Mukono were identified and trained in video storytelling and research. The use of video has an established track record in research and development as a participatory communication practice and method that can transcend entrenched barriers to inclusion of marginal voices and perspectives (Walker 2018). It achieves this while also delivering effective horizontal and vertical communication and brokering effective links that otherwise may not exist. In Mukono, rural theme partners used basic video making as a way of overcoming and subverting the traditional one-way knowledge exchange processes sometimes found in rural research and communication. By engaging the farmer champions identified by CAN-U and providing training in visual storytelling, researchers initiated a conversation between farmers and their district government.

The focus of this conversation was on how their agricultural and fishing practices need government support to respond to challenges in the context of an increasingly unpredictable climate. This approach allows farmers to work in their own language, using their own cultural idioms, in a way that enables their own subjectivity to surface. Building this bridge for twoway communication between farmers and their district government initiates a process in our pilot communities that allows farmers to overcome the inclusion hurdle in adaptation planning.

At national level, the advocacy work targets the Parliament of Uganda, the national planning agencies and the departments of agriculture, climate change and finance (see Fig. 8.2). The farmer champions have also met with the NPA and held a dialogue on key planning needs for future adaptation to climate change. These connections were identified through the initial stakeholder mapping activities conducted by CAN-U. These highlighted the decision-making influence points targeted by the

\footnotetext{
${ }^{1}$ See: http://www.walker.ac.uk/about-walker/news-events/walker-institute-teamcontributes-to-ugandan-national-environment-bill/
} 


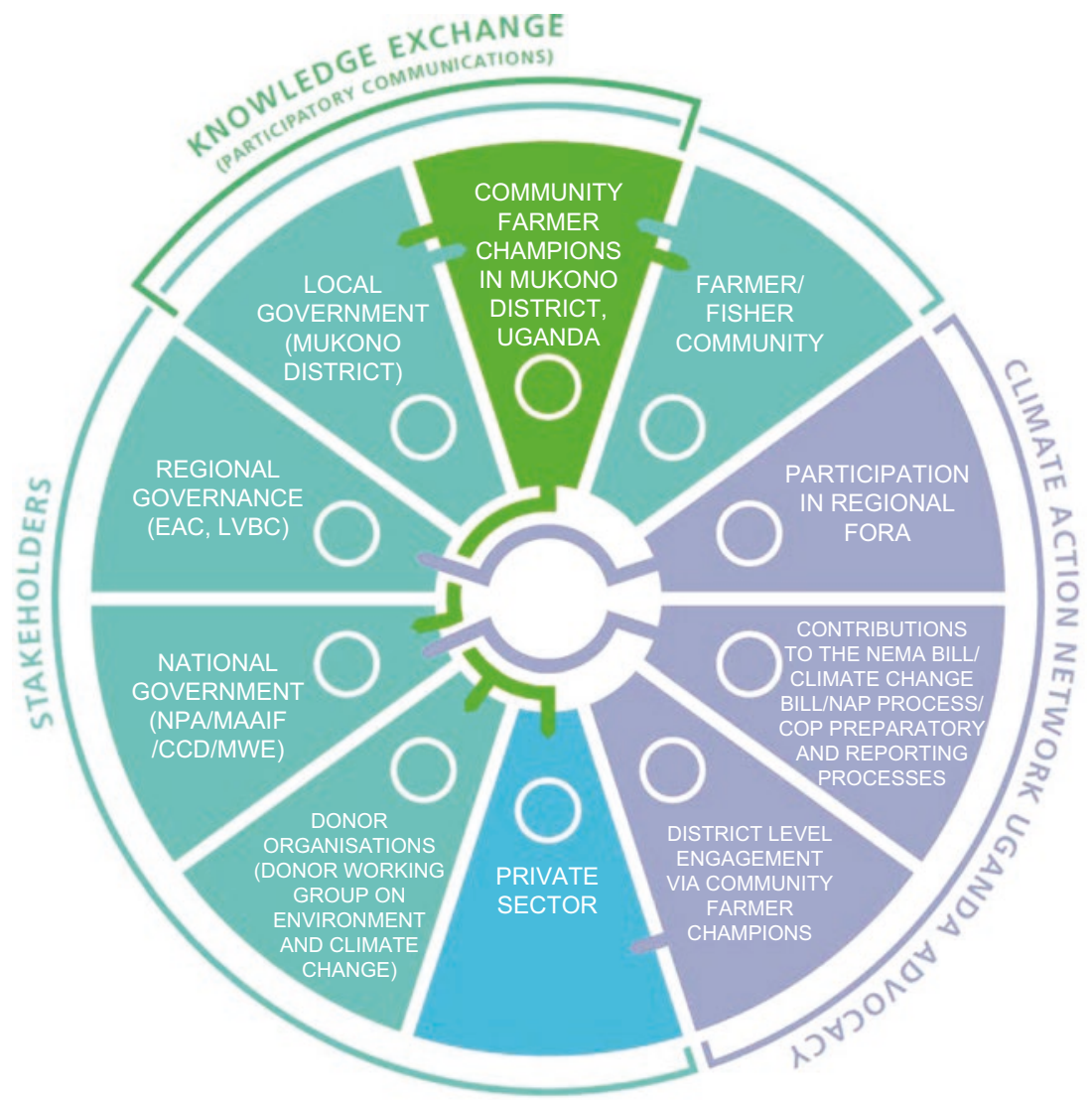

Fig. 8.2 Schematic showing the development of the multi-level networks under the HyCRISTAL rural pilot. Key: CCD Climate Change Department, COP Conference of the Parties under the UNFCCC, EAC East African Community, LVBC Lake Victoria Basin Commission, MAAIF Ministry of Agriculture, Animal Industry and Fisheries, MWE Ministry of Water and Environment, NAP National Adaptation Plan, NEMA National Environment Management Authority

integration of participatory communications and the CAN-U advocacy plan and are illustrated in Fig. 8.2.

At district level, the farmer champions have interacted with district leaders, agriculture extension workers and national and sub-national leaders to inform and influence budgeting and planning for rural adaptation 
and, in particular, increased access to agricultural extension services. The Mukono District local budget is showing signs of response towards financing and supporting climate needs of smallholder farmers with funding for targeted agriculture extension services increasing by $18 \%$ in the financial year 2019-20. Further to this, HyCRISTAL smallholder champion farmers have reported increased access to extension services in their communities in the last financial year.

\section{Discussion and Conclusion: The Importance of Multi-stakeholder Approaches for Climate-Informed Rural Decision-Making}

Our HyCRISTAL pilot study in Mukono set out to answer the question 'What information do local policymakers need now to reduce vulnerability and enhance resilience?' Our experience highlights the importance of multi-stakeholder approaches and the generation of a 'knowledge ecosystem' that combines physical and social science methods and data to generate context-specific information to inform decision-making. The approach we have described shows how established research tools rooted in both the qualitative and quantitative research traditions can combine to provide a deeper, policy relevant understanding of fundamental questions of climate change, resilience and adaptation. Lessons learned included how communities, sector services and non-governmental organisations (NGOs) might better plan their activities based on likely scenarios that reflect opportunities, risks and outcomes in agriculture, disaster risk reduction, adaptation and resilience.

If rural adaptation is to be effective, then it cannot take the form of prescriptive actions determined by outsiders and subsequently imposed upon rural communities. Even if all the evidence suggests a certain course of action should be taken, without input from the rural communities themselves, there is the danger that adaptation merely expands marginalisation through the reproduction of historical power imbalances resulting from remote decision-making and the elite custodianship of information. For rural adaptation to be effective, it needs to reflect and more critically understand local experience and perspectives, based on knowledge sharing (both information and the skills required to interpret it), to allow for devolved decision-making, and to be as inclusive as possible, given unequal power structures. 
To answer our question asked earlier, the convergence of various strands of research and communication in the rural pilot-from local to national to regional-provides policymakers with the types of information they need. This promotes consideration of scenarios and the taking of actions based on a systems-based understanding derived from multiple and diverse sources of knowledge. This is continuing to enable policymakers across all levels to make better informed short- (e.g. revised allocation of district budget to support targeted extension services) and long-term decisions (e.g. adoption of revised clauses in the Uganda National Environment Bill) related to rural adaptation. It also allows specific consideration of the problem of under-investment in the rural economy and rural populations through the evidence provided by the rural pilot.

By understanding adaptation to drivers of change as a political and socio-economic process, and not simply a scientific one, then the notion of science-led solutions fails the fit-for-purpose test. Direct engagement with decision-makers, empowered at all levels with access to relevant information, is imperative, and central to this is a strategy for, and execution of, effective communication.

Finally, our rural pilot study has highlighted the need to critically interrogate and understand the implications of adaptation and resilience as policy responses to climate change in poorer rural communities. Failure to do this runs the risk of promoting solutions that are ineffective or even counter-productive. Active involvement of local populations in the governance process and advocacy through, for example, video storytelling, provides opportunities to surface the needs, education and aspirations of marginalised rural communities, which include growing numbers of largely neglected, 'left behind' youth. This re-framing offers the potential to contribute to and enhance national capabilities for more effective and inclusive climate risk management and provides civil society with new opportunities for policy engagement in sustainable development.

\section{REFERENCES}

Boyd, E., \& Cornforth, R. J. (2013). Building adaptive institutions for climate resilience: Lessons of early warning and RANET in Africa. Successful Adaptation to Climate Change: Linking Science and Policy in a Rapidly Changing World, 201-219.

Burgin, L., Walker, G., Cornforth, R., Rowell, D., Marsham, J. H., Semazzi, F., Sabiiti, G., Ainslie, A., Araujo, J., Ascott, M., Clegg, D., Clenaghan, A., 
Lapworth, D., Lwiza, K., Macdonald, D., Petty, C., \& Wainwright, C. (2019). FCFA HyCRISTAL climate narrative rural infographic and brief. https://doi. org/10.5281/zenodo.3257288

Chambers, R., \& Conway, G. R. (1992). Sustainable rural liveliboods: Practical concepts for the 21st century. IDS Discussion Paper, 296. Retrieved from https://www.ids.ac.uk/publications/sustainable-rural-livelihoods-practicalconcepts-for-the-21st-century/

Cornforth, R. J., Clegg, D., \& Petty, C. (2020). The integrated database for African policymakers (Version v2.0). https://doi.org/10.5281/ zenodo.3701722

Ellis, F. (2000). Rural Livelihoods and Diversity in Developing Countries. Oxford: Oxford University Press.

Jarvis, A., Lau, C., Cook, S., Wollenberg, E., Hansen, J., Bonilla, O., \& Challinor, A. (2011). An integrated adaptation and mitigation framework for developing agricultural research: Synergies and trade-offs. Experimental Agriculture, 47(2), 185-203. https://doi.org/10.1017/S0014479711000123.

Markandya, A., Cabot-Venton, C., \& Beucher, O. (2015). Economic assessment of the impacts of climate change in Uganda: Final study report. Ministry of Water and Environment. Retrieved from https://cdkn.org/wp-content/ uploads/2015/12/Uganda_CC-economics_Final-Report2.pdf

Mitchell, T., \& Maxwell, S. (2010). Policy brief: Defining climate compatible development. Climate \& Development Knowledge Network. Retrieved from https://cdkn.org/wp-content/uploads/2012/10/CDKN-CCD-Planning_ english.pdf

Scoones, I. (1998). Sustainable rural livelihoods: A framework for analysis. SDL Working Paper Series, IDS Working Paper 72. Retrieved from https://www. ids.ac.uk/publications/sustainable-rural-livelihoods-a-framework-foranalysis/

Seaman, J. A., Sawdon, G. E., Acidri, J., \& Petty, C. (2014). The household economy approach. Managing the impact of climate change on poverty and food security in developing countries. Climate Risk Management, 4, 59-68. https:// doi.org/10.1016/j.crm.2014.10.001.

Sen, A. (1981). Poverty and famines: An essay on entitlement and deprivation. Oxford: Oxford University Press.

Uganda Government. (2015a). Second national development plan (NDPII) 2015/16-2019/20. Theme: Strengthening Uganda's Competitiveness for Sustainable Wealth Creation, Employment and Inclusive Growth. National Planning Authority. Retrieved from http://npa.go.ug/wp-content/uploads/ NDPII-Final.pdf

Uganda Government. (2015b). Uganda national climate change policy. Theme: Transformation. Ministry of Water and Environment. Retrieved from https:// www.mwe.go.ug/sites/default/files/library/National\%20Climate $\% 20$ Change\%20Policy\%20April\%202015\%20final.pdf 
UNOCHA. (2019). UGANDA: FLOODS \& LANDSLIDES, Flash Update No. 1. Retrieved from https://reliefweb.int/sites/reliefweb.int/files/resources/ ROSEA_20191219_Uganda_Floods_FlashUpdate\%231.pdf

Walker, G. (2018). Movie making as critical pedagogy: Conscientization through visual storytelling (1st ed.). London: Palgrave Macmillan. https://doi. org/10.1007/978-3-319-96926-8.

Young, H. R., Cornforth, R. J., Todman, L.C., Miret, J. A., Shepherd, T. G., Petty, C., O'Sullivan, D. M., Wagstaff, C., Mason, O., \& Talwisa, M. (2020). Policy brief: Assessing the impact of climate change on sweet potato in Uganda. Walker Institute. https://doi.org/10.5281/zenodo.3836642

Open Access This chapter is licensed under the terms of the Creative Commons Attribution 4.0 International License (http://creativecommons.org/licenses/ by $/ 4.0 /$ ), which permits use, sharing, adaptation, distribution and reproduction in any medium or format, as long as you give appropriate credit to the original author(s) and the source, provide a link to the Creative Commons licence and indicate if changes were made.

The images or other third party material in this chapter are included in the chapter's Creative Commons licence, unless indicated otherwise in a credit line to the material. If material is not included in the chapter's Creative Commons licence and your intended use is not permitted by statutory regulation or exceeds the permitted use, you will need to obtain permission directly from the copyright holder.

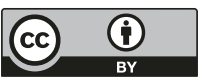

